\title{
Effect of moisture content on textural attributes of dried figs
}

\author{
Sara Ansari ${ }^{1 *}$, Neda Maftoon-Azad ${ }^{2}$, Asgar Farahnaky ${ }^{3}$, Ebrahim Hosseini $^{4}$, and Fojan Badii ${ }^{5}$ \\ ${ }^{1}$ Department of Food Science and Technology, Kazerun Branch, Islamic Azad University, Kazerun, Iran \\ ${ }^{2}$ Fars Research Center for Agriculture and Natural Resources, Zarghan, Iran \\ ${ }^{3}$ Department of Food Science and Technology, School of Agriculture, Shiraz University, Shiraz, Iran \\ ${ }^{4}$ Department of Food Science and Technology, Science and Research Branch, Islamic Azad University, Tehran, Iran \\ ${ }^{5}$ Department of Food Engineering and Postharvest Technology, Agricultural Engineering Research Institute, Karaj, Iran
}

Received January 7, 2014; accepted September 29, 2014

\begin{abstract}
A b s t r a c t. Due to their soft texture consumers prefer moist figs, which has motivated fig processors to increase the production of this product. However, as water enhances the browning reaction rate, moisture content optimisation of moist figs is very important. Processed figs must have suitable texture softness with browning kept to a minimum. The purpose of this study was to examine the effect of moisture content on the textural attributes of dried figs. Hardness, compression energy, gradient, gumminess and chewiness of fig samples decreased with moisture content exponentially, whereas the trend of springiness and cohesiveness with change of moisture content was nearly constant. Moreover, in the texture profile analysis plot of rehydrated figs, the presence of negative area is an indication of adhesiveness which was zero in control dried figs. The results of the texture profile analysis tests proved the existence of a critical moisture content of about $18.4 \%$, above which no significant effect of moisture content on textural parameters was found. The glass-rubber transition results from differential scanning calorimeter may explain the different texture profile analysis attributes of dried figs compared with rehydrated figs.

$\mathrm{K}$ e y w o r d s: moisture content, texture profile analysis, dried fig, glass transition
\end{abstract}

\section{INTRODUCTION}

For a long time, food scientists and food producers have recognised texture as an important quality factor influencing the consumers' acceptance of foods. Texture can be defined as a group of physical parameters deriving from structural food elements which are perceived mostly by touch. Texture is related to deformation, comminution and flow of food under force, and objectively expressed as functions of mass, time and distance (Szczesniak, 1998).
Texture is a sensory feature and is composed of several textural properties including mechanical (hardness, chewiness and viscosity), geometrical (particle size and shape) and chemical (moisture and fat content) characteristics (Bourne, 1980). It could be measured by fundamental, imitative and empirical ways. Objective measurement of food texture predominantly involves an analysis of the mechanical behaviour of food materials including measurements of load distance characteristics using mechanical devices, and the assessment of subjective characteristics using a suitable texture profiling method. Instrumental texture profile analysis (TPA), applicable to both sensory and instrumental measurements, is a method used to determine the texture of solids and semi-solids by simulating or imitating the repeated biting or chewing of foods (Szczesniak, 1998; Szczesniak-Surmacka, 2002). Several characteristics such as cellularcomponents, biochemical constituents, watercontent and cell wall composition influence texture in fruits and vegetables. Therefore, any external factors affecting these characteristics can change texture and, by extension, final product quality (Guine and Barroca, 2011). Textural changes occur during the processing of plant materials or certain physiological events related to tissue and cell micro-structural changes (Guine and Barroca, 2011; Unal et al., 2013).

As a sensory property, hardness is determined as the force required to compress a substance between molar teeth or between tongue and palate; cohesiveness - the degree to which a substance is compressed between the teeth before it breaks; springiness - the degree to which a product returns 
to its original shape after compression with the teeth; adhesiveness - the force required to remove the material that adheres to the mouth during normal eating process; chewiness - the length of time required to masticate the sample applying constant rate of force to reduce it to a consistency suitable for swallowing; and gumminess - the energy required to disintegrate a food to a state ready for swallowing (Szczesniak-Surmacka, 2002).

Drying is the most widely employed method for food preservation, and is based on water removal. Although the physicochemical and microbiological stability of foods improves upon drying, some undesirable texture and colour changes take place. Most dried food materials must be rehydrated before direct consumption or use in the manufacture of other products. In the rehydration process the dried products come into contact with water or other liquids such as fruit juices, sucrose, glucose or glycerol solutions (Krokida and Marinos-Kouris, 2003; Maldonado et al., 2010). It is more desirable for the rehydration process to be as fast as possible in order to retain suitable structural and chemical characteristics and to acquire better qualityreconstituted products (flavour, texture and nutritional quality) (Sanjuan et al., 2001). Textural properties of rehydrated products depend on temperature, pre-drying time and rehydration processes. The rehydration bath temperature is the most important factor affecting the rehydration process, so that at higher water temperatures more rapid rehydration occurs (Cox et al., 2012).

One of the major leading producers and exporters of dried fruits in the world is Iran, with dried figs being the most important. Figs are of great nutritional importance as they are an outstanding source of carbohydrates, minerals, essential amino acids and vitamins (Veberic et al., 2008). They contain one of the highest concentrations of polyphenols among the commonly consumed foods and beverages (Vinson, 1999). According to FAO statistics, the world fig production is about $1184884 \mathrm{t}$ and Iran, with $76414 \mathrm{t}$, ranks third in the world after Turkey (254 $838 \mathrm{t}$ ) and Egypt (884 972 t) (FAO, 2012). About $85 \%$ of Iran total fig production is for dry consumption. Dried figs have become an increasingly important product as they are advantageous to both industrial users and individual consumers, offering longer shelf life, higher economic value and ease of use in consumption compared to their use in fresh form.

Most of the fig fruits in Iran are produced in the Fars region. The 'Sabz' type, as the most widely produced variety in Iran, is also the main cultivar for dried figs. The main problems with dried figs are a decrease in food quality and safety due to hazardous microorganisms, aflotoxin B1 and some storage pests such as Ephestia or Plodia (Oztekin et al., 2006). Moreover, the process of drying figs may lead to important textural changes such as hardness and shrinkage, which may have a negative impact on their marketability. One way to increase the consumer acceptability of this valuable agricultural commodity is rehydration and the production of intermediate-moisture figs. In addition, browning is a major defect during storage of this type of product. Therefore, optimising the moisture level of this product taking into account both texture and browning reaction is of great interest to fig processors.

Water, the most ubiquitous plasticizer, affects the glass-to-rubber transition temperatures ( $\mathrm{Tg}$ ) of many synthetic and natural amorphous polymers (particularly at low moisture contents), and depresses Tg that can be advantageous or disadvantageous to material properties, processing and stability (Levine and Slade, 1988). Glass transition is a power-ful tool for understanding the quantification of water mobility in foods and for controlling the shelf-life of products. Besides Tg, water activity $\left(a_{w}\right)$ is another important tool to predict available water in foods and the physical state of solid foods (Roos, 1995). However, it has been shown that $\mathrm{Tg}$ is superior to $\mathrm{a}_{\mathrm{w}}$ due to the unsuitability of the latter to evaluate the shelf life of some food products. At temperatures below Tg, all food products are considered to be stable, and there will be no considerablechangeintheirphysicochemicalorbiologicalqualities (Delgado and Sun, 2002). However, at temperatures above Tg the molecular mobility and free volume of the product increase, and the physical and physicochemical deteriorative reactions may speed up in the rubbery state (Slade and Levine, 1991; Roos, 2003). The purpose of this study was to determine the effect of moisture content on the textural properties of sun-dried figs using texture profile analysis (TPA). Moreover, determination of critical moisture content below which texture characteristics of figs show great changes is to be addressed.

\section{MATERIALS AND METHODS}

Dried figs (Sabz variety) were purchased from Estahban Fig Research Centre (Fars province, southern Iran). They were packed in polyethylene bags and stored at $4^{\circ} \mathrm{C}$ until analysis. Initial moisture content of dried figs was $6.2 \%$.

Dried fig samples, with a fig to water ratio of $1: 3(\mathrm{w} / \mathrm{w})$, were rehydrated in distilled water at constant temperatures $\left(25,60,70,80\right.$ and $\left.90^{\circ} \mathrm{C}\right)$ for different time intervals using a thermostable water bath $\left( \pm 0.1^{\circ} \mathrm{C}\right)$. After rehydration, the samples were removed from the bath and weighed after blotting with tissue paper in order to remove superficial water. They were then packed and stored until moisture conditioning (Ansari et al., 2014). The moisture content of the samples was measured according to the Association of Official Analytical Chemists methods (AOAC, 1990).

Texture profile analysis tests were carried out using a texture analyzer (Texture Analyser, TA Plus, Stable Microsystems, Surrey, England) with a load cell of $30 \mathrm{~kg}$. Each sample corresponding to a rehydration time after conditioning was subjected to a double compression force test using a cylindrical probe having dimensions greater than the sample dimensions. The samples were compressed 


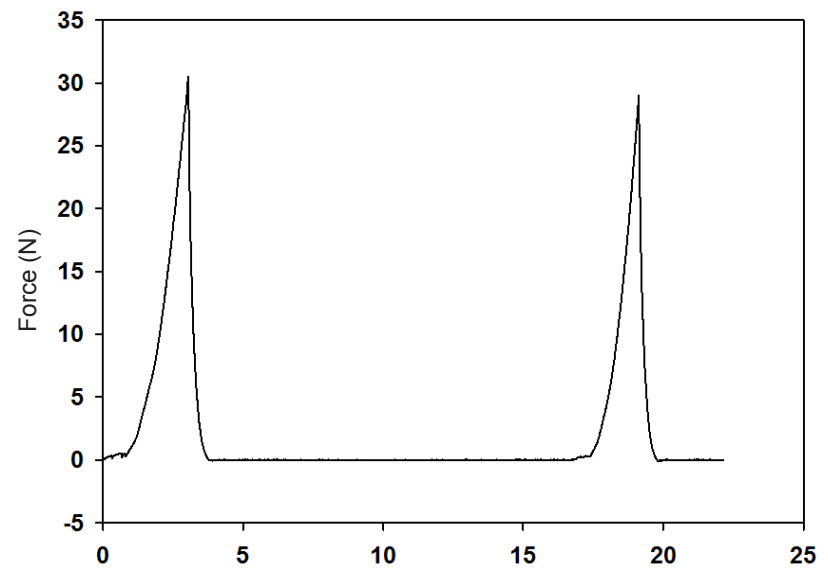

b

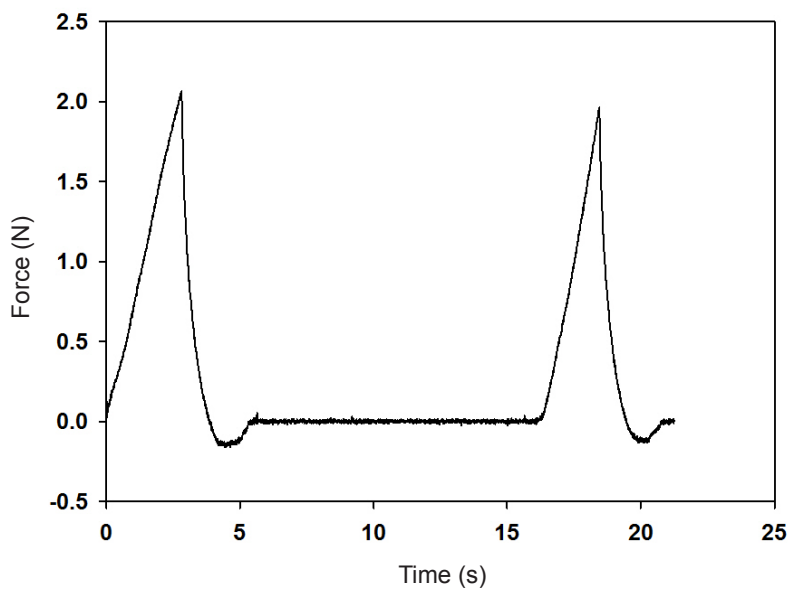

Fig. 1. Texture profile analysis curve obtained for: a - dried fig $(6.2 \%)$ and $\mathrm{b}$ - rehydrated fig at $60^{\circ} \mathrm{C} 15 \mathrm{~min}^{-1}(24.1 \%)$.

to $20 \%$ of their original height by two consecutive compressions using a cylindrical probe of $100 \mathrm{~mm}$ diameter at a speed of $1 \mathrm{~mm} \mathrm{~s}^{-1}$. The time interval between the two compression cycles was $10 \mathrm{~s}$. Using the Texture Exponent Lite supplied by the manufacturer, textural parameters were calculated from the TPA curves as shown in Fig. 1. The textural parameters considered in the present study are defined as follows (Bourne, 1978):

Hardness $(\mathrm{N})$ is the maximum load applied to the samples during the first compression. Compression energy ( $\mathrm{N} \mathrm{s}$ ) is the area under force versus time until maximum force obtained. Cohesiveness (dimensionless) is the ratio of the area under the second peak to that under the first peak. Springiness (dimensionless) is understood as the reversed sample deformation in the second compression obtained as the ratio of the distance of detected height of sample on the second compression to that of the original compression. Gumminess $(\mathrm{N})$ is determined by multiplying hardness and cohesiveness; chewiness $(\mathrm{N} \mathrm{mm})$ is the product of gumminess and springiness. The function gradient (dimensionless) calculates the gradient of the slope of the curve between the two selected points. All textural measurements were performed at room temperature $\left(22 \pm 2^{\circ} \mathrm{C}\right)$ with four replicates of each sample.

The glass transition ( $\mathrm{Tg}$ ) and melting temperature ( $\mathrm{Tm})$ of moist figs were determined using a Perkin Elmer Pyris Diamond differential scanning calorimeter (DSC) (Cambridge, UK), equipped with a refrigerated cooling system which efficiently maintained the experimental temperature. The instrument was calibrated for temperature and enthalpy with indium $\left(\mathrm{Tm}\right.$, onset $=156.6^{\circ} \mathrm{C}$, Delta $\mathrm{H}$ $\left.=28.45 \mathrm{~J} \mathrm{~g} \mathrm{~g}^{-1}\right)$ and cyclohexane $\left(\mathrm{T}_{\mathrm{m} \text {, onset }}=6.5^{\circ} \mathrm{C}\right)$ according to manufacturer recommendation. In this experiment, weighed samples $(30 \mathrm{mg})$ were sealed in a pre-weighed high-pressure stainless steel pan, cooled to $-50^{\circ} \mathrm{C}$, and then heated at a heating rate of $10^{\circ} \mathrm{C} \mathrm{min}{ }^{-1}$ to $150^{\circ} \mathrm{C}$. After the first heating, the samples were cooled at a rate identical to the rate of heating $\left(10^{\circ} \mathrm{C} \mathrm{min}^{-1}\right)$, and then the second heating cycle was performed. An empty stainless steel pan was used as the reference. Tg was determined from the onset, midpoint and endpoint of the step change in the specific heat of the sample in the second heating run, while Tm was reported as onset, peak and endpoint temperatures obtained from the first heating scan.

Analysis of variance (ANOVA) of TPA parameters of samples with different moisture content was applied in order to determine if there was a significant difference between the means $(\alpha=0.5)$. Duncan multiple range test was used to compare the means using IBM SPSS statistic software, version 19.

\section{RESULTS AND DISCUSSION}

Rehydration kinetics of sun-dried figs, which is defined as changes in moisture content as a function of rehydration time at different temperatures, is shown in Fig. 2. As seen, the moisture content of the samples for all rehydration curves increased as rehydration time progressed, with an initial steep increase followed by a decrease in rehydration rate. This behaviour may be related to decreases in the driving force of water movement as rehydration progresseduntilthesystemreachedequilibrium. Moreover, byincreasing the rehydration temperature from 25 to $90^{\circ} \mathrm{C}$, both the rehydration rate and the amount of water absorbed increased.

Figure 1 shows the TPA obtained for the sun-dried and rehydrated figs, respectively. It is obvious that the TPA plot of dried figs consists of two force peaks during the two consecutive compressions. However, in the rehydrated sample a negative area is seen in the TPA plot upon upstroking the probe after the first compression. The existence of this negative area in some rehydrated samples indicates that the adhesiveness of samples depends on the adhesion degree (or stickiness) of the fig sample to the probe. Indeed, in rehydrated samples with moisture content of $13.5-30 \%$ the adhesiveness value was nearly constant (0.1-0.2), after which a small increase in moisture content led to a large decrease in adhesiveness (approaching zero). 


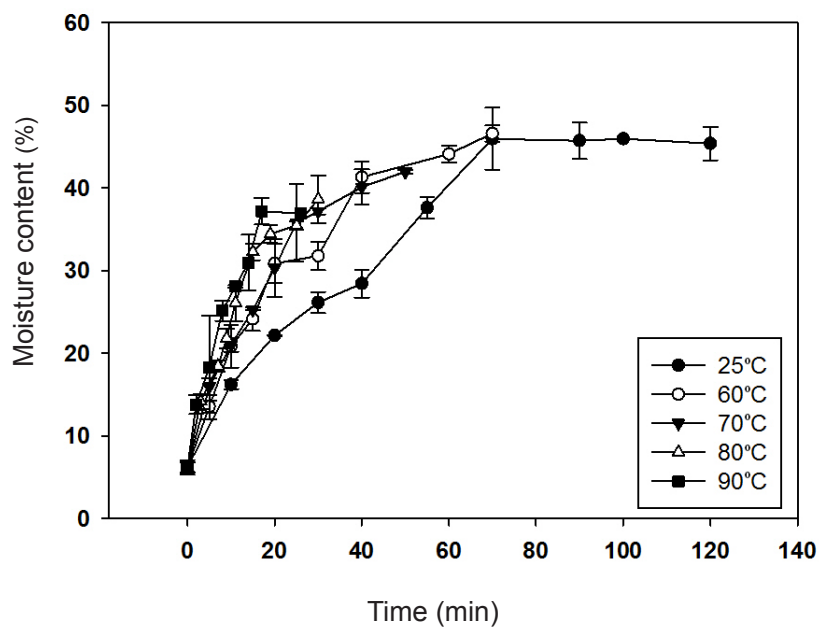

Fig. 2. Rehydration rate curve for dried figs at different temperatures $\left(25-90^{\circ} \mathrm{C}\right)$.

This may be related to the sticky nature of sugars which retains this property in water until a certain water level has been reached (about 30\%), after which the viscosity of the water-sugar mixture, and hence the stickiness, drops suddenly. Washing sugars out and away from the figs surface at longer rehydration times may also contribute to reductions in adhesiveness beyond $30 \%$.

The changes in hardness, gradient and compression energy of sun-dried figs rehydrated at different times and temperatures as a function of moisture content are presented in Fig. 3 and Table 1. The table shows that as the moisture content increased, the hardness of the samples decreased at a rapid softening rate at the beginning. After dried fig rehydration, the hardness decreased from $31 \mathrm{~N}$ to the constant value of 2-4 N. This behaviour may be related to the transition of the glassy dried fig (tough to deform) into rubbery rehydrated fig (easy to deform), which will be explained in more detail in the following section. Rahman and Al-farsi (2005) and Seow and Thevamalar (1988) examined the hardness of date flesh and rice-based products as a function of moisture content and also attributed this behaviour to the rubbery-leathery transition. The rubbery-leathery transition was expressed when the force required to compress the sample suddenly increased with a decrease in moisture content. Leather state is defined as a relatively tough material which is hard to deform; this state occurs often as temperatures approach Tg. Moreover, the hardness values as obtained revealed no significant differences between rehydration temperatures. However, when this data was analysed according to the rehydration time (and so the moisture content), a significant difference was observed between samples containing 6.2 and $16.2 \%$ with other samples at $25^{\circ} \mathrm{C}$ as well as at temperatures of 60 , 70,80 and $90^{\circ} \mathrm{C}$.
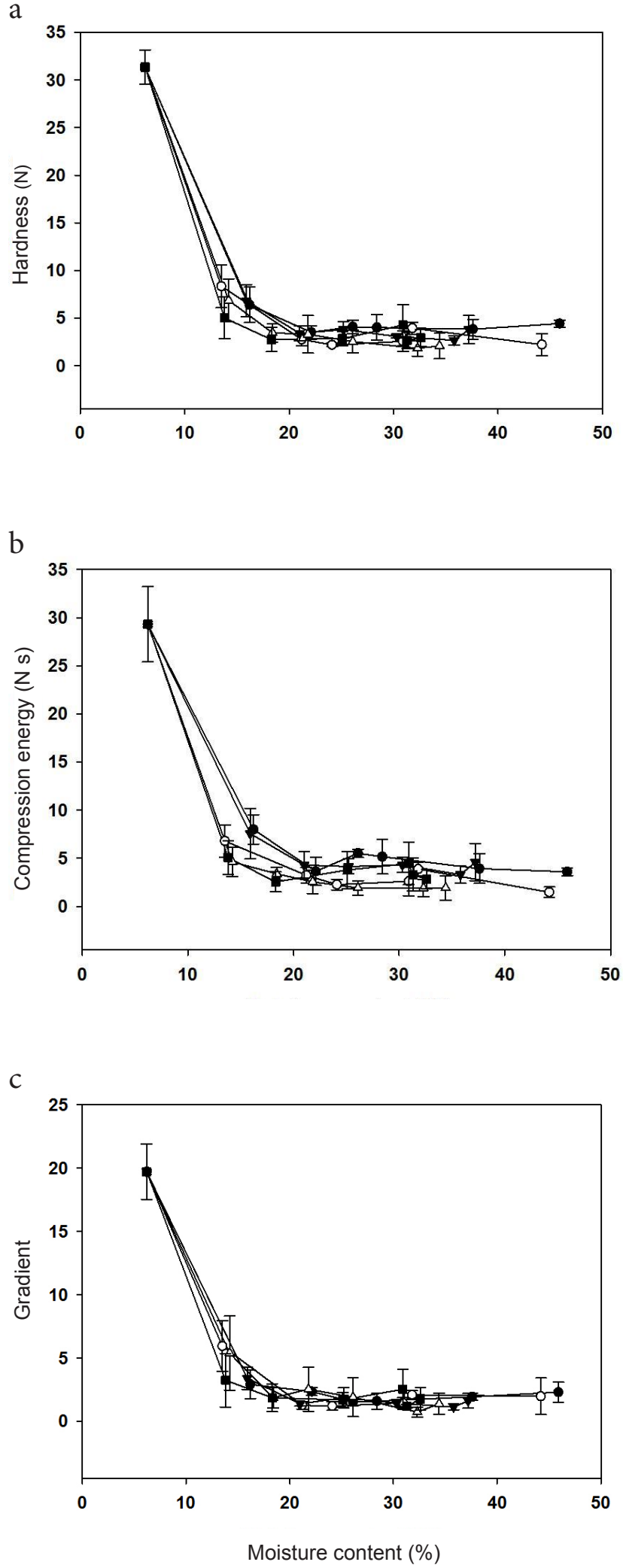

Fig. 3. Variation of hardness (a), compression energy (b) and gradient (c) as a function of moisture content. Legend as in Fig. 2. 
T a b l e 1. Texture profile analysis (TPA) of dried figs rehydrated at different times and temperatures

\begin{tabular}{|c|c|c|c|c|c|c|}
\hline $\begin{array}{l}\text { Temperature } \\
\left({ }^{\circ} \mathrm{C}\right)\end{array}$ & $\begin{array}{c}\text { Moisture } \\
\text { content }(\%)\end{array}$ & $\begin{array}{l}\text { Hardness } \\
\text { (N) }\end{array}$ & Gradient & $\begin{array}{l}\text { Compression } \\
\text { energy (N s) }\end{array}$ & $\begin{array}{l}\text { Gumminess } \\
\text { (N) }\end{array}$ & $\begin{array}{l}\text { Chewiness } \\
(\mathrm{N} \text { mm })\end{array}$ \\
\hline \multirow{7}{*}{25} & 6.2 & $31.35 \mathrm{a} \pm 1.8$ & $19.71 \mathrm{a} \pm 2.2$ & $29.30 \mathrm{a} \pm 3.9$ & $22.55 \mathrm{a} \pm 2.7$ & $18.47 \mathrm{a} \pm 3.4$ \\
\hline & 16.2 & $6.38 b \pm 1.8$ & $2.92 b \pm 1.1$ & $8.00 \mathrm{~b} \pm 1.5$ & $4.18 b \pm 1.2$ & $3.78 b \pm 1.2$ \\
\hline & 22.1 & $3.52 \mathrm{c} \pm 0.7$ & $2.36 b \pm 0.3$ & $3.64 \mathrm{c} \pm 1.4$ & $3.07 b \pm 0.4$ & $2.39 b \pm 0.5$ \\
\hline & 26.1 & $4.08 \mathrm{c} \pm 0.7$ & $1.54 b \pm 0.3$ & $5.52 b c \pm 0.4$ & $2.66 b \pm 0.3$ & $2.04 b \pm 0.1$ \\
\hline & 28.4 & $4.02 c \pm 1.3$ & $1.60 \mathrm{~b} \pm 0.6$ & $5.16 b c \pm 1.8$ & $2.68 b \pm 0.8$ & $2.42 b \pm 0.9$ \\
\hline & 37.6 & $3.83 \mathrm{c} \pm 1.0$ & $1.94 b \pm 0.3$ & $3.93 \mathrm{c} \pm 1.5$ & $2.80 \mathrm{~b} \pm 0.6$ & $2.53 b \pm 0.5$ \\
\hline & 45.9 & $4.42 b c \pm 0.4$ & $2.30 \mathrm{~b} \pm 0.8$ & $3.59 \mathrm{c} \pm 0.4$ & $3.32 b \pm 0.1$ & $2.51 b \pm 0.2$ \\
\hline \multirow{7}{*}{60} & 6.2 & $31.35 \mathrm{a} \pm 1.8$ & $19.72 \mathrm{a} \pm 2.2$ & $29.30 \mathrm{a} \pm 3.9$ & $22.53 a \pm 2.7$ & $18.47 \mathrm{a} \pm 3.3$ \\
\hline & 13.5 & $8.35 b \pm 2.2$ & $5.94 b \pm 2.0$ & $6.79 b \pm 1.6$ & $6.28 b \pm 1.6$ & $5.00 \mathrm{~b} \pm 1.1$ \\
\hline & 21.2 & $2.76 c \pm 0.7$ & $1.27 \mathrm{c} \pm 0.3$ & $3.23 c \pm 0.8$ & $1.84 \mathrm{c} \pm 0.4$ & $1.60 \mathrm{c} \pm 0.4$ \\
\hline & 24.1 & $2.18 \mathrm{c} \pm 0.2$ & $1.21 \mathrm{c} \pm 0.3$ & $2.27 \mathrm{c} \pm 0.6$ & $1.63 c \pm 0.3$ & $1.48 \mathrm{c} \pm 0.4$ \\
\hline & 30.9 & $2.56 \mathrm{c} \pm 1.1$ & $1.46 \mathrm{c} \pm 0.4$ & $2.61 \mathrm{c} \pm 1.5$ & $1.86 \mathrm{c} \pm 0.8$ & $1.56 c \pm 0.7$ \\
\hline & 31.8 & $3.95 \mathrm{c} \pm 0.6$ & $2.10 \mathrm{c} \pm 0.3$ & $3.88 \mathrm{bc} \pm 0.7$ & $2.85 c \pm 0.5$ & $2.49 \mathrm{c} \pm 0.5$ \\
\hline & 44.2 & $2.22 \mathrm{c} \pm 1.1$ & $1.98 \mathrm{c} \pm 1.4$ & $1.47 \mathrm{c} \pm 0.5$ & $1.73 \mathrm{c} \pm 0.9$ & $1.22 \mathrm{c} \pm 0.7$ \\
\hline \multirow{7}{*}{70} & 6.2 & $31.35 \mathrm{a} \pm 1.8$ & $19.71 \mathrm{a} \pm 2.2$ & $29.30 \mathrm{a} \pm 3.9$ & $22.54 \mathrm{a} \pm 2.7$ & $18.47 \mathrm{a} \pm 3.3$ \\
\hline & 15.9 & $6.82 b \pm 1.7$ & $3.40 \mathrm{~b} \pm 0.9$ & $7.56 b \pm 2.6$ & $4.73 b \pm 1.1$ & $3.71 b \pm 1.0$ \\
\hline & 21.0 & $3.40 \mathrm{c} \pm 0.8$ & $1.39 \mathrm{c} \pm 0.2$ & $4.30 b c \pm 1.4$ & $2.33 c \pm 0.5$ & $1.75 b \pm 0.5$ \\
\hline & 25.2 & $3.79 \mathrm{c} \pm 0.9$ & $1.86 b c \pm 0.8$ & $4.14 b c \pm 0.8$ & $2.76 b c \pm 0.7$ & $2.08 \mathrm{~b} \pm 0.6$ \\
\hline & 30.3 & $3.08 \mathrm{c} \pm 0.2$ & $1.45 c \pm 0.3$ & $4.32 b c \pm 0.8$ & $2.12 \mathrm{c} \pm 0.1$ & $1.77 b \pm 0.1$ \\
\hline & 35.8 & $2.66 c \pm 0.5$ & $1.14 \mathrm{c} \pm 0.2$ & $3.30 \mathrm{c} \pm 0.9$ & $1.88 \mathrm{c} \pm 0.4$ & $1.56 \mathrm{~b} \pm 0.3$ \\
\hline & 37.2 & $3.79 \mathrm{c} \pm 1.5$ & $1.62 b c \pm 0.6$ & $4.60 \mathrm{bc} \pm 1.9$ & $2.67 b c \pm 0.9$ & $2.21 b \pm 0.7$ \\
\hline \multirow{7}{*}{80} & 6.2 & $31.35 \mathrm{a} \pm 1.8$ & $19.71 \mathrm{a} \pm 2.2$ & $29.30 \mathrm{a} \pm 3.9$ & $22.54 \mathrm{a} \pm 2.7$ & $18.47 \mathrm{a} \pm 3.3$ \\
\hline & 14.2 & $6.86 b \pm 2.2$ & $5.39 b \pm 2.9$ & $4.62 b \pm 1.5$ & $5.11 b \pm 1.4$ & $4.40 \mathrm{~b} \pm 1.2$ \\
\hline & 18.4 & $3.46 \mathrm{c} \pm 1.0$ & $1.87 \mathrm{c} \pm 0.8$ & $3.39 b \pm 0.7$ & $2.45 b c \pm 0.8$ & $2.37 b c \pm 0.8$ \\
\hline & 21.8 & $3.30 \mathrm{c} \pm 2.0$ & $2.54 b c \pm 1.7$ & $2.55 b \pm 1.2$ & $2.48 b c \pm 1.4$ & $2.23 b c \pm 1.3$ \\
\hline & 26.1 & $2.54 \mathrm{c} \pm 1.2$ & $1.91 \mathrm{c} \pm 1.5$ & $1.91 b \pm 0.8$ & $1.99 \mathrm{c} \pm 1.0$ & $1.58 b c \pm 0.8$ \\
\hline & 32.3 & $1.83 \mathrm{c} \pm 0.8$ & $0.73 c \pm 0.4$ & $1.89 b \pm 0.9$ & $1.37 \mathrm{c} \pm 0.7$ & $1.20 \mathrm{c} \pm 0.6$ \\
\hline & 34.4 & $2.08 \mathrm{c} \pm 1.3$ & $1.39 \mathrm{c} \pm 0.8$ & $1.91 b \pm 1.3$ & $1.67 \mathrm{c} \pm 1.1$ & $1.54 b c \pm 1.2$ \\
\hline \multirow{7}{*}{90} & 6.2 & $31.35 b \pm 1.8$ & $19.71 \mathrm{a} \pm 2.2$ & $29.30 \mathrm{a} \pm 3.9$ & $22.54 \mathrm{a} \pm 2.7$ & $18.47 \mathrm{a} \pm 3.3$ \\
\hline & 13.8 & $5.01 b \pm 2.2$ & $3.25 b \pm 2.1$ & $5.07 \mathrm{~b} \pm 1.7$ & $3.42 b \pm 1.8$ & $2.30 \mathrm{~b} \pm 1.5$ \\
\hline & 18.3 & $2.74 b \pm 1.3$ & $1.86 \mathrm{~b} \pm 1.1$ & $2.54 b \pm 1.0$ & $1.84 b \pm 0.8$ & $1.36 \mathrm{~b} \pm 0.8$ \\
\hline & 25.1 & $2.84 b \pm 0.7$ & $1.69 b \pm 0.6$ & $3.79 b \pm 1.9$ & $1.98 b \pm 0.3$ & $1.74 b \pm 0.6$ \\
\hline & 30.9 & $4.27 b \pm 2.1$ & $2.54 b \pm 1.6$ & $4.45 b \pm 2.2$ & $3.03 b \pm 1.5$ & $2.59 b \pm 1.4$ \\
\hline & 31.3 & $2.65 b \pm 0.9$ & $1.19 b \pm 0.2$ & $3.30 \mathrm{~b} \pm 1.7$ & $1.82 b \pm 0.6$ & $1.43 b \pm 0.7$ \\
\hline & 32.6 & $2.92 b \pm 0.9$ & $1.79 b \pm 0.9$ & $2.83 b \pm 1.0$ & $2.10 b \pm 0.6$ & $1.59 b \pm 0.6$ \\
\hline
\end{tabular}


T a b l e 1. Continuation

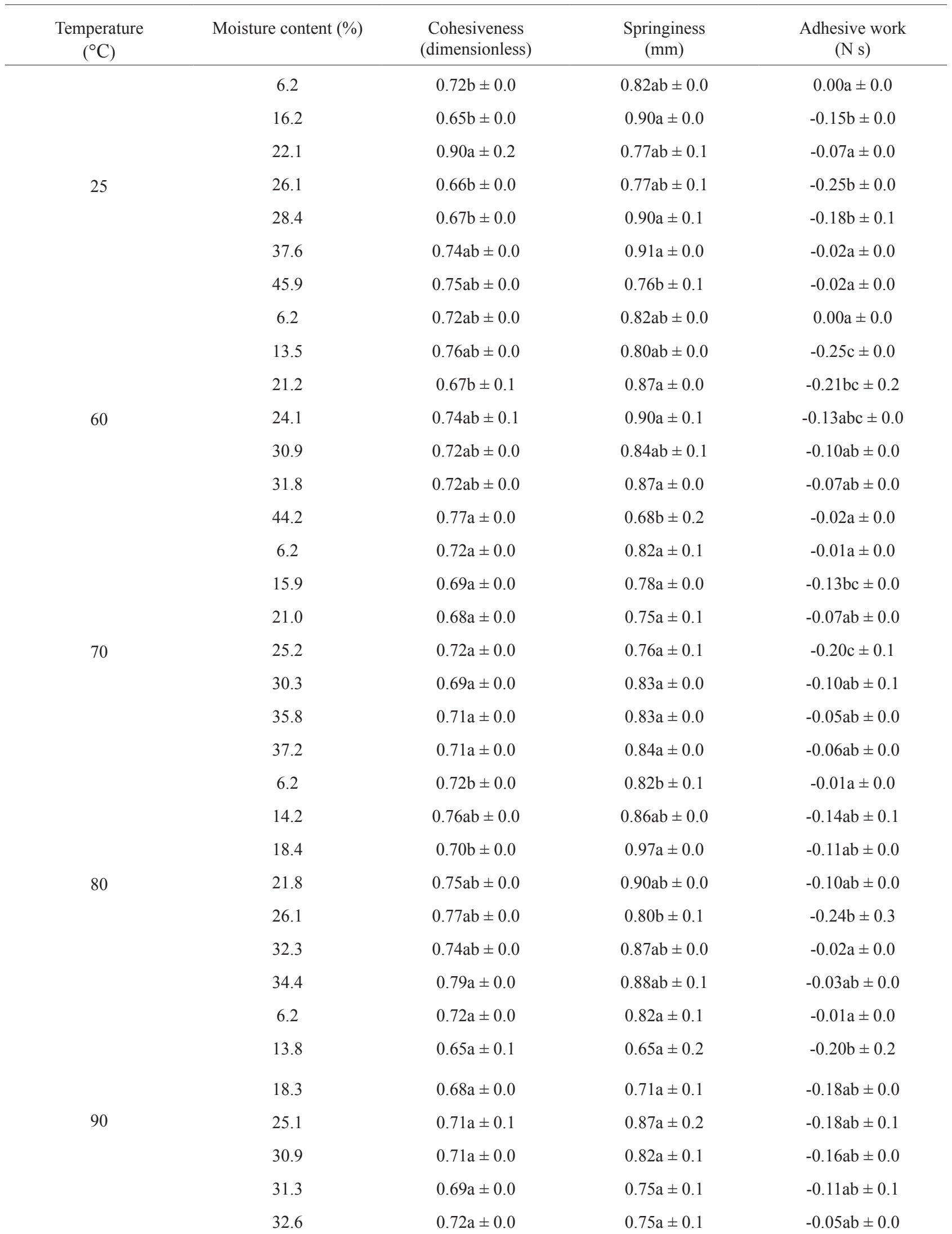

Data are reported as mean \pm st.dev. of four replicates. Mean values denoted in each column by different letters are significantly different $(\mathrm{a}<0.05)$ as estimated with Duncan test $(\alpha=0.05)$. 

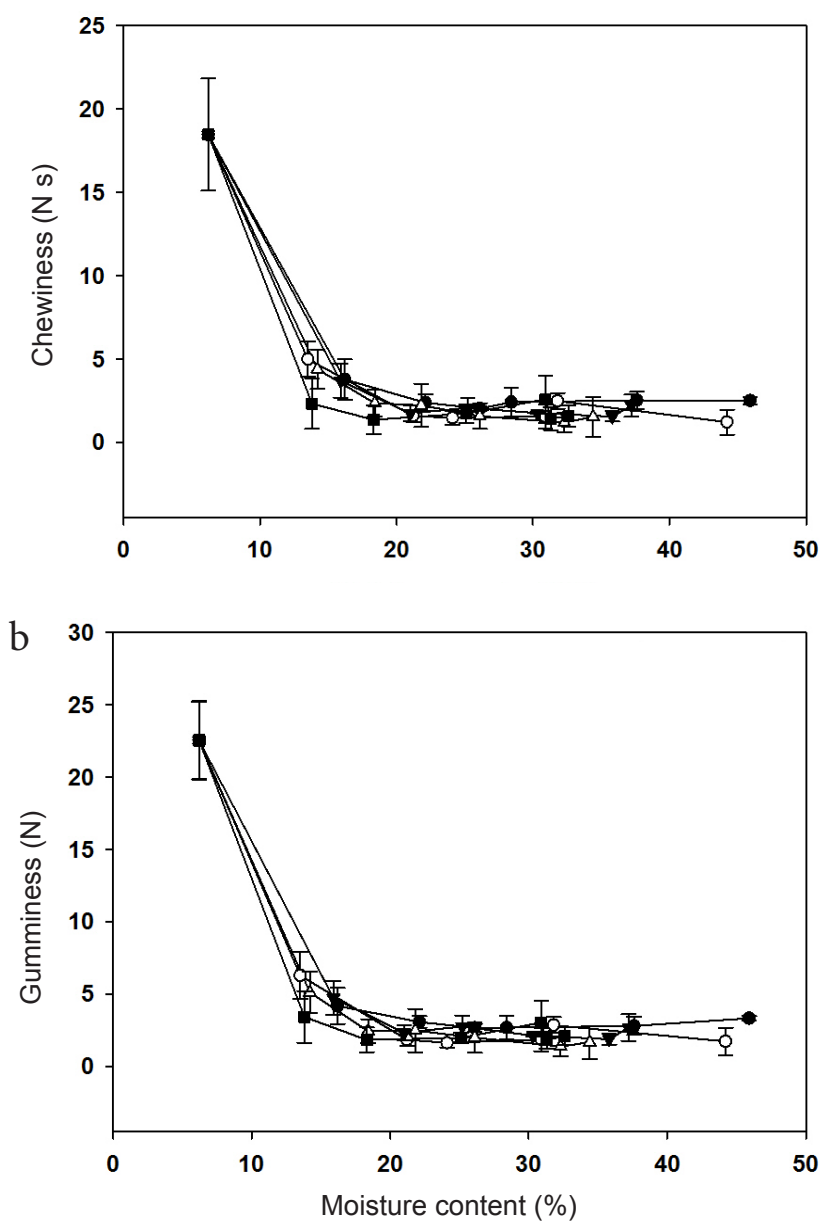

Fig. 4. Variation of chewiness (a) and gumminess (b) as a function of moisture content. Legend as in Fig. 2.

The compression energy and gradient parameters of dried and rehydrated figs as a function of moisture content at different rehydration temperatures are also shown in Fig. 3b, c. The figure indicates that, similar to hardness, the compression energy and gradient of all samples were reduced as a function of moisture content. Compression energy, which is an indicator of the energy required to compress the samples to $20 \%$ of their original height (in this study), was about $29.3 \mathrm{~N}$ s in dried figs compared to approximately 2-4 N s in rehydrated ones. This implies that rehydrated figs would require less energy than dried figs, and that dried figs are softened during the rehydration process.

Table 1 shows the effect of moisture content on cohesiveness and springiness of dried and rehydrated figs. Cohesiveness represents how well the sample withstands a second deformation relative to the first one. It is worth noting that cohesiveness of rehydrated dried figs was rather constant (about 0.75), indicating that the figs were texturally cohesive. This effect may be explained by the presence of elasticity in fig cellular structure which contributes to its deformation recovery after load removal. It may be that compression energy was stored in the cellulose and hemicelluloses in the plant cell structure, causing the material to return to its initial state after force removal. Plant cell walls can be considered a fibre-reinforced composite consisting of rigid cellulose microfibrils (as isotropic component) crosslinked by a hemicelluloses and pectin matrix (isotropic component) (Athmaselvi et al., 2012; Hansen et al., 2011; Peaucelle et al., 2011). Organized into the network with the cellulose microfibrils, cross-linking can increase the tensile strength of the cellulose, whereas the coextensive networks of pectins provide the cell wall with the ability to resist compression. Many researchers have stated that plant cell walls exhibit viscoelastic properties: they retain shape after deformation, but with a time delay (Peaucelle et al., 2011).

Springiness (sometimes also referred to as 'elasticity') indicates the elastic recovery that occurs when the compression force is removed (or the degree to which a product returns to its original shape after compression with the teeth). High springiness (close to one) appears when the sample is elastic and so it returns back to its original shape after compression, whereas low springiness (near to zero) results from tissue damage after compression (viscous nature of samples). The average springiness for dried figs is $0.82 \%$ and for rehydrated figs in the range of $0.65-0.9 \%$ (average $0.78 \%$ ), without significant change between different rehydration times and temperatures. The values are nearly similar, indicating that rehydration treatment did not change the recovery in height after the product has been compressed by the teeth during mastication. Moreover, considering the proximity of springiness to the one value, the elastic component in rehydrated dried figs dominates the viscous component. In practical terms, if the sample is compressed to $20 \%$ of its initial height, $78 \%$ of its deformation is recovered after force removal.

Figure 4 presents the effect of moisture content on chewiness and gumminess of figs rehydrated at different temperatures, indicating that the values of both were derivatives of hardness, cohesiveness and springiness. Chewiness is the quality of simulating the energy required to masticate a solid sample to a steady state for swallowing, while the energy required to disintegrate a solid food to a steady state for swallowing is defined as gumminess. The change in hardness, chewiness and gumminess ran parallel to each other. Considering Fig. 3a and Table 1, the magnitude of hardness range (1.8-31 N) was far higher than those of cohesiveness $(0.65-0.9)$ and of springiness values $(0.65-0.9 \mathrm{~mm})$ (the two other parameters in the definition of chewiness and gumminess). However, it does not mean that those parameters are the same; in fact, they represent different textural sensory attributes. With an increase of moisture content, chewiness and gumminess decreased without any significant difference between rehydration temperatures of $25-90^{\circ} \mathrm{C}$. In dried state, the figs show an average chewiness and gumminess 
of $18 \mathrm{~N} \mathrm{~mm}$ and $22.5 \mathrm{~N}$; however, after rehydration these values decreased to constant values of 1-2 $\mathrm{N} \mathrm{mm}$ and 1-3 $\mathrm{N}$, respectively.

Fig adhesiveness (the work necessary to overcome the attractive forces between the surface of the fig and the surface of the probe with which the food comes into contact) at different moisture contents is also shown in Table 1. The maximum adhesiveness $(-1.06 \mathrm{~N} \mathrm{~s})$ was found in rehydrated figs with a moisture content of $16.2 \%$, and its value decreased as moisture content increased. However, in dried fig this parameter was nearly equal to zero due to the absence of a negative area in the TPA plot. Indeed, adhesiveness is more of a surface characteristic that depends on acombinedeffectofadhesiveandcohesiveforces, aswellasviscosity and viscoelastic characteristics (Adhikari et al., 2001). The glass to rubbery transition, as explained in the following section, may be responsible for this type of behaviour.

Overall, an increase in dried fig moisture content up to $18.4 \%$ considerably decreased the values of all the parameters measured in the TPA tests (except cohesiveness and springiness). Statistical analysis indicated that further increase in fig moisture content within the range of $18.4-46 \%$ did not affect the values of hardness, work, gradient, gumminess, springiness and adhesiveness. In a research of Figiel and Tanjner-Czopek (2006), who examined the effect of moisture content on texture of candy, the critical moisture content of about $2 \%$ was reported.

Dehydrated, low-moisture and frozen foods, which are very sensitive to changes in moisture content and temperature, are typically in an amorphous metastable state either as a very viscous amorphous matrix (known as 'glass') or as a more mobile amorphous structure (known as rubber). The changes from the glassy to the rubbery state occur at Tg which is specific for each material and strongly depends on moisture content and its chemical composition (Levine and Slade, 1992; Sa et al., 1999). All these different physical states of the material are well described in a phase state diagram showing transition temperatures (eg glass transition and melting) as a function of water content (Rahman, 2006). Figure 5 presents the state diagram obtained for sun-dried figs (or the effect of moisture content on the glass transition temperature $(\mathrm{Tg})$ ). In the low and intermediate moisture content domain $\left(\mathrm{a}_{\mathrm{w}}<0.81\right)$, studied in this article, the plasticizing effect of water on the $\mathrm{Tg}$ was evident, with a reduction of $\mathrm{Tg}$ by increasing moisture content. Similar results regarding the effect of $\mathrm{a}_{\mathrm{w}}$ on $\mathrm{Tg}$ were obtained by Moraga et al. (2011), Sa et al. (1999), and Telis and Sorbal (2002), for freezedried/air-dried tomato, freeze-dried apple and banana slices and fresh/processed apples, respectively.

Glass transition is an example of second-order transition which is characterised by a discontinuity in a material's physical, mechanical, electrical, thermal and other properties. The typical DSC curve of sun-dried figs with different moisture content is shown in Fig. 6. As can be seen, at all

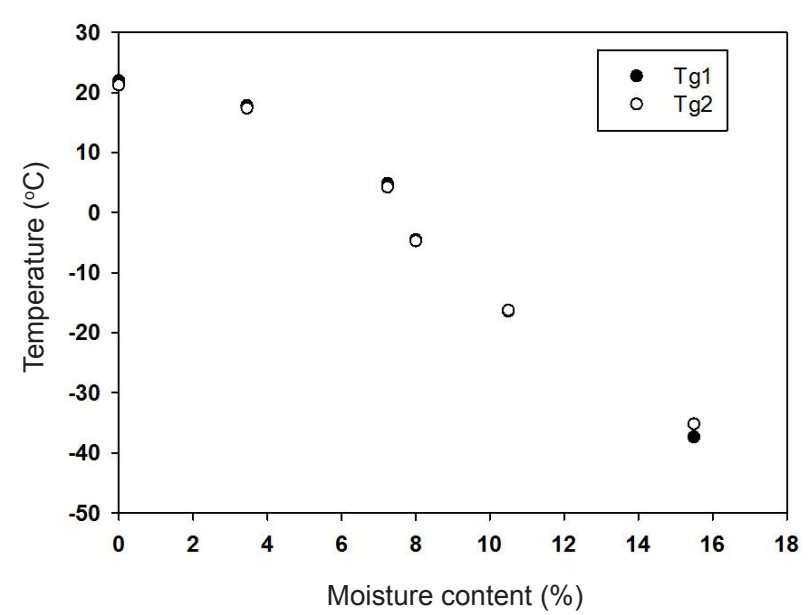

Fig. 5. State diagram of dried figs (Tg of dried-figs with two replicates).

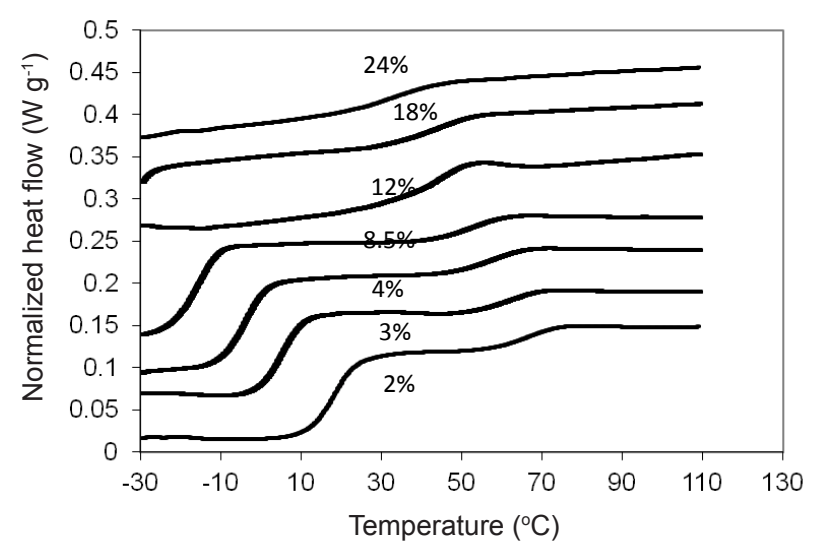

Fig. 6. DSC traces of dried figs at different moisture contents.

moisture contents, glass transition occurs over a temperature range (not a point), and the onset, midpoint or endset temperature of the change in heat flow may be considered as $\mathrm{Tg}$. Considering the moisture content of figs rehydrated at different temperatures (13.5-45.9\%), all rehydrated figs are in rubbery state while the sun-dried figs (control sample) are in glass-rubber transition region. According to Huang (1999), the physical state of the structural matrix ranges from the glassy state to and through the following regions: glass-rubber transition, rubbery plateau, rubbery flow, and viscous flow, which greatly influences the rheological properties of food products. Even during the glass transition range alone, the rheological properties can change as much as 1000 times (Huang, 1999). Indeed, when the material transforms from the glassy to the rubbery state, the molecules become mobile, which can alter food structure and microstructure, crystallisation, rates of diffusion, stabilisation of microbial cells and spores, and chemical and biochemical reactions (Slade and Levine, 1991). This may explain the intensive loss of hardness as well as the 
occurrence of stickiness in rehydrated figs compared with dried ones; however, in all rubbery state samples, the texture properties did not change significantly.

\section{CONCLUSIONS}

1. A moisture based process control is a must for fig processing during rehydration, as during the rehydration process of dried figs extra rehydration above the critical moisture content does not soften the texture significantly. However more moisture may increase browning reactions substantially.

2. A negative area in the texture profile analysis plot of rehydrated figs is an indication of adhesiveness which was zero in control dried figs.

3. Based on the results of the texture profile analysis tests, a critical moisture content equal to $18.4 \%$ was proved. An increase in dried fig moisture content in the range of $6.2-18.4 \%$ caused a significant decrease in the texture profile analysis parameters studied (ie hardness, work, gradient, gumminess and chewiness). Whereas, an increase in moisture content above $18.4 \%$ did not cause any significant decreases in the values of the mentioned parameters.

4. The glassy to rubbery transition measured from the DSC method may explain the texture changes of figs with different moisture content.

5. Considering the typical thermogram of differential scanning calorimeter all rehydrated figs are in rubbery state while the sun-dried figs are in glass-rubber transition region.

\section{REFERENCES}

Adhikari B., Howes T., Bhandari B.R., and Truong V., 2001. Stickiness in foods: a review of mechanisms and test methods. Int. J. Food Prop., 4 (1), 1-33.

Ansari S., Maftoon-Azad N., Hosseini E., Farahnaky A., and Asadi Gh., 2014. Modeling the Rehydration Behavior of Dried Figs. J. Agric. Sci. Technol., (in press).

AOAC, 1990. Official Methods of Analysis, 15th ed. Association of Official Analytical Chemist, Washington, DC, USA.

AthmaselviK.A.,Alagusundaram K.,Kavitha C.V., andArumuganathan T., 2012. Impact of pretreatment on colour and texture of watermelon rind. Int. Agrophys., 26, 235-242.

Bourne M.C., 1978. Texture profile analysis. Food Technol., 32, 62-66.

Bourne M.C., 1980. Texture evaluation of horticultural crops. Hort. Sci., 15, 51-56.

Cox S., Gupta S., and Abu-ghannam N., 2012. Effect of different rehydration temperatures on the moisture, content of phenolic compounds, antioxidant capacity and textural properties of edible Irish brown seaweed. LWT - Food Sci. Technol., 47, 300-307.

Delgado A.E. and Sun D.W., 2002. Desorption isotherms and glass transition temperature for chicken meat. J. Food Eng., $55,1-8$.

FAO, 2012. Statistical database. (Available from http:// www.fao. org)

Figiel A. and Tajner-Czopek A., 2006. The effect of candy moisture content on texture. J. Food Serv., 17, 189-195.
Guine R.P.F. and Barroca M.J., 2011. Influence of freeze-drying treatment on the texture of mushrooms and onions. Croat. J. Food Sci. Tech., 3 (2), 26-31.

Hansen S.L., Ray P.M., Karlsson A.O., Jorgensen B., Borkhardt B., Petersen B.L., and Ulvskov P., 2011. Mechanical Properties of Plant Cell Walls Probed by Relaxation Spectra. Plant Physiol., 155, 246-258.

Huang V.T., 1999. Effect of glass transitions on the rheological properties of food polymers. Macromol. Symp., 140, 125-135.

Krokida M.K. and Marinos-Kouris D., 2003. Rehydration kinetics of dehydrated products. J. Food Eng., 57, 1-7.

Levine H. and Slade L., 1988. Water as plasticizer: physicochemical aspects of low-moisture polymeric systems. In: Water Science Review 3 (Ed. F. Franks), Cambridge University Press, Cambridge, MA, USA.

Levine H. and Slade L., 1992. Glass Transition in foods. In: Physical Chemistry of Foods (Eds H.G. Schwartzberg, R.W. Hartel), Marcel Dekker, New York, USA.

Maldonado S., Arnau E., and Bertuzzi M.A., 2010. Effect of temperature and pretreatment on water diffusion during rehydration of dehydrated mangoes. J. Food Eng., 96, 333-341.

Moraga G., Talens P., Moraga M.J., and Martinez-Navarrete N., 2011. Implication of water activity and glass transition on the mechanical and optical properties of freeze-dried apple and banana slices. J. Food Eng., 106 (3), 212-219

Oztekin S., Zorlugence B., and Zorlugence F., 2006. Effects of ozone treatment on microflora of dried figs. J. Food Eng., 75, 396-399.

Peaucelle A., Braybrook S.A., Guillou L.L., Bron E., Kuhlemeier C., and Hofte H., 2011. Pectin-Induced changes in cell wall mechanics underlie organ initiation in arabidopsis. Curr. Biol., 21, 1720-1726.

Rahman M.S.H. and Al-farsi S.A., 2005. Instrumental texture profile analysis (TPA) of date flesh as a function of moisture content. J. Food Eng., 66, 505-511.

Rahman M.S., 2006. State diagram of foods: Its potential use in food processing and product stability. Trends Food Sci. Tech., 17, 129-141.

Roos Y., 1995. Water activity and glass transition temperature: How do they compliment and how do they differ. In: Food Preservation by Moisture ControlFundamentals andApplications (Eds. G.V. Barbosa-Canovas and J. Welti-Chanes). Technomic Publishing Co., Lancaster, UK.

Roos Y.H., 2003. Thermal analysis, state transitions and food quality. J. Therm. Anal. Calorim., 71, 197-203.

Sa M.M., Figueiredo A.M., and Sereno A.M., 1999. Glass transitions and state diagrams for fresh and processed apple. Thermochim. Acta, 329, 31-38.

Sanjuan N., Carcel J.A., Clemente G., and Mulet A., 2001. Modelling of the rehydration process of brocolli florets. Eur. Food Res. Technol., 212, 449-453.

Seow C.C. and Thevamalar K., 1988. Problems associated with traditional Malaysian starch-based intermediate moisture foods. In: Food Preservation by Moisture Control (Ed. C.C. Seow). Elsevier Applied Science, London, UK.

Slade L. and Levine H., 1991. Beyond water activity: Recent advances based on an alternative approach to the assessment of food quality and safety. Crit. Rev. Food Sci., 30, $115-360$. 
Szczesniak A.S., 1998. Effect of storage on texture. In: Food Storage stability (Eds I.A. Taub, R.P. Singh). CRC Press, Boca Raton, FL, USA.

Szczesniak-Surmacka A., 2002. Texture is a sensory property. Food Qual. Prefer., 13, 215-225.

Telis V.R.N. and Sobral P.J.A., 2002. Glass transitions for freezedried and air-dried tomato. Food Res. Int., 35, 435-443.
Unal H., Alpsoy H.C., and Ayhan A., 2013. Effect of the moisture content on the physical properties of bitter gourd seed. Int. Agrophys., 27, 455-461.

Veberic R., Colaric M., and Stampar F., 2008. Phenolic acids and flavonoids of fig fruit (Ficus carica L.) in the northern Mediterranean region. Food Chem., 106, 153-157

Vinson J.A., 1999. The functional food properties of figs. Cereal Food World, 44(2), 82-87. 